\title{
Performance of AFWR Synchronous Motor as Changing from AFWR Synchronous Generator
}

\author{
Abdul Multi ${ }^{1}$, M. Dwi Trisno ${ }^{1}$, Budiyanto ${ }^{2}$ \\ \{amulti@istn.ac.id ${ }^{1}$, yan.budiyanto@yahoo.com ${ }^{2}$ \} \\ Institut Sains Dan Teknologi Nasional (ISTN), Jl.Moh Kahfi II Jagakarsa Jakarta Selatan, Jakarta, \\ Indonesia $^{1}$, Electrical Department, Jakarta Muhammadiyah University (UMJ), Jakarta, Indonesia ${ }^{2}$
}

\begin{abstract}
The tests should be performed for the three phase synchronous generator of Axial Flux Wound Rotor (AFWR) which has been planned and constructed. The tests are also performed for the motor deriving from that AFWR generator. The behavior of the generator and the motor can be known after those testing. Hence, by using one machine, it can be operated for resulting electricity and for rotating mechanic. The load examining is applied for the synchronous machine. The electrical load can be attached to the generator after it is running and the testing output is achieved. Likewise, the mechanical load can be connected to the motor after it is supplied by the power source and the examining outcome is gained. The mesurement in those tests are executed the nominal load. From the testing output of AFWR synchronous generator at rated load having $0.5 \mathrm{~mm}$ air gap yielding the efficiency of $61.61 \%$ with the rotor voltage of 10.85 $\mathrm{V}$. Whereas, from the examining outcome of AFWR synchronous motor with the terminal voltage of $380 \mathrm{~V}$ and the field voltage of $9.53 \mathrm{~V}$ is attained $73.58 \%$.
\end{abstract}

Keywords: AFWR; generator; motor; efficiency.

\section{Introduction}

The electric motor is used for changing electrical energy into mechanical energy. While the generator for changing mechanical energy into electrical energy. Motor and generator can be realized on the same machine, but on the two reversed process. A synchronous motor is similar to a synchronous generator, but the direction of current flow is reversed. Meanwhile the direction of current flow in the machine is reversed, the direction of power flow in the stator of the motor may be expected to reverse also. In the motor, the three phase current flowing in the armature winding yields a rotational magnetic intensity which interrelates with the rotor magnetic intensity, creating rotating force in the machine. While in the generator, the rotational magnetic intensity from the field windings induces ac voltages of three phase into its stator armature coils.

\subsection{Changing a motor from a generator}

It is exciting that one electrical machine can be operated as generator or motor. The dissimilarity among the generator and the motor is related to the externally used powers are in the path of movement (generator) or contrary to the path of movement (motor). Electrically, as 
the induced voltage is greater than the terminal voltage, the machine deeds as a generator, and when the induced voltage is lesser than the terminal voltage, the machine deeds as a motor [1]. When the machine operates as a motor or a generator, together induced power (motor operation) and induced current (generator operation) are appeared in any times. It is commonly correct of entirely machines the two deeds are owned, and it is merely the relative posistions of the outside power with attention to the posistion of movement that assign if the entire machine performs as a motor or as a generator.

The elementary difference between motor and generator operation in synchronous machines can be understood either in the magnetic field diagram or in the phasor diagram. In a generator, $E_{A}$ locates ahead of $V_{\phi}$ and $B_{R}$ locates ahead of $B_{\text {net }}$. In a motor, $E_{A}$ locates behind $\mathrm{V}_{\phi}$ and $\mathrm{B}_{\mathrm{R}}$ locates behind $\mathrm{B}_{\text {net }}$. In a motor the induced torque is in the path of motion, and in a generator the induced torque is an opposite torque opposing the direction of motion. The phasor diagram related to generator and motor operation is shown in Figure 1 dan 2 respectively [2].

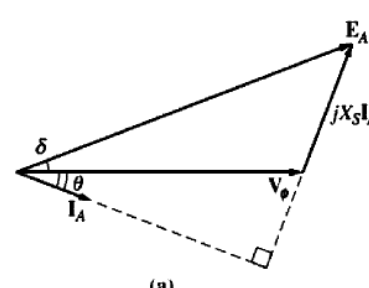

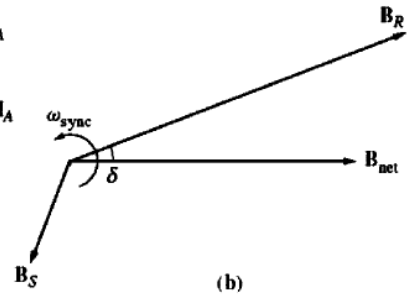

(b)

Fig. 1. (a) Phasor diagram of a synchronous generator. (b) The related magnetic field diagram.

In an electrical system, an electric machine is needed to be able to change its function as both generator and motor. The change of this function can be done rapidly as it is needed. For example, the motor used to drive an electric traction can be turned into a generator when braking. Similarly, a motor can behave as a motor in the pumped storage hydro power station and on high rise building elevators.

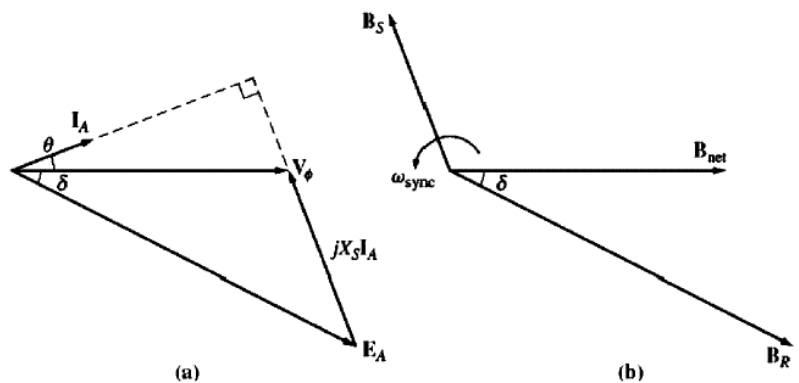

Fig. 2. (a) Phasor diagram of a synchronous motor. (b) The related magnetic field diagram. 


\subsection{The AFWR machine}

Initially, the machine designed is AFWR synchronous generator. Therefore, it is needed typical ratings of on a synchronous machine for designing. It is related to required specifications of machine operation as seen in Table 1.

The generator planned is three phase axial flux wound rotor (AFWR) synchronous generator with controlling the field current. It is small-scale capacity with terminal voltage, power and speed are $380 \mathrm{~V}, 1 \mathrm{~kW}$ and $750 \mathrm{rpm}$ respectively. The stator and the rotor are made from slotted lamination core [3].

Table 1. needed specifications of machine action.

\begin{tabular}{ll}
\hline Parameters & Values \\
\hline Line Voltage & $380 \mathrm{~V}$ \\
Total of poles & 8 \\
Frequency & $50 \mathrm{~Hz}$ \\
Cos phi & 0.83 \\
\hline
\end{tabular}

The generator possesses one stator wound with two side of slotted iron core which inserted among two rotor. The axial flux (AF) machine commonly utilizes permanent magnets attached on the rotating part. Exchanging the permanent magnet with a coil in the rotating part, causes it might to regulate the flux by changing the power moving into the coil of the moving part [4].

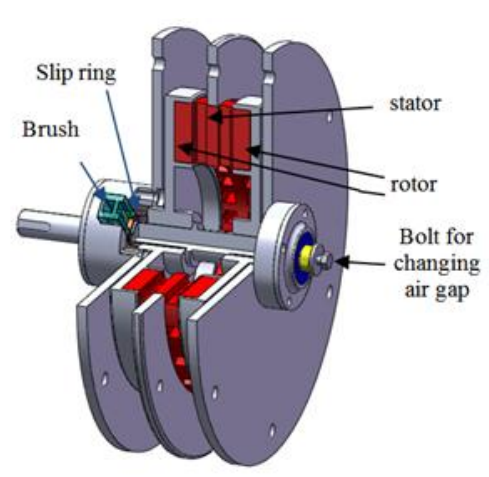

Fig. 3. The designed AFWR synchronous generator.

A machine with axial flux having winding in the field is denoted to as an axial flux wound rotor. A construction of the planned AFWR machine is displayed in Picture 3. This generator contains of doubble field coils which two coils are linked to in parallel. The armature of the AFWR generator is placed among two differing field coils. The two side moving patrs is solely named double rotors with holes of winding are placed on the surfaces of the stationary part and at the lamination core of moving part. 
In fundamental, the magnetic intensity plan of AFPM machines is alike to its radial flux PM (RFPM) mate to rod-shaped moving parts. One of the machines is a disc-type machine and the other is cylindrical-type machine. The axial flux (AF) machines possess a total of different benefits over radial flux machines [5].

Once fabricating all parts of the generator are completed, they can be assembled to make the AFWR generator. The AFWR generator that has been congested is displayed in Figure 4. After the generator is tested to know its performance, the generator is then operated as a motor and tests are performed on the motor. The motor is supplied by the rated voltage during the testing that is $380 \mathrm{~V}$.

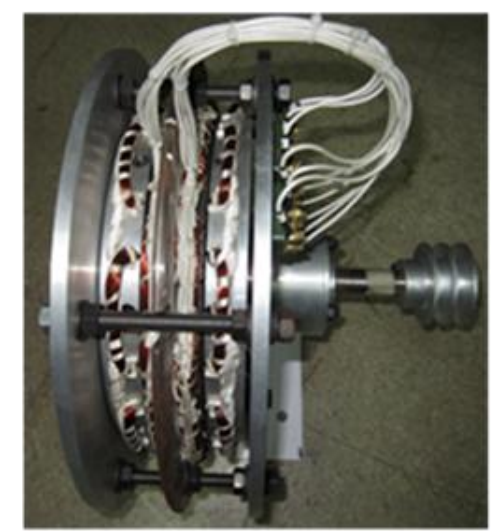

Fig. 4. The assembled AFWR generator.

\section{Methodology/Experimental}

\subsection{The machine design}

The outcome of computations become the base for constructing the generator. The stator and rotor are two part to start the manufacturing. The core, slots, brushes and slipring are portions of the stator and the rotor, whereas the the shaft and the bearing are mechanical portion. The software of Matlab can be used for computing the design. After computing, by using the software of Solidwork, the two dimensional or three dimensional drawing can be made. Two dimensional Solidworks picture can be utilized for basing the manufacturing.

The axial and radial flux machine formulas are utilized as base for computing the synchronous genrator plan. The circuit of electric and magnetic and mechanical parts are also computed by those formulas. For correctness and exactness computations are utilized the software of Matlab, while for figuring the machine and the portions are applied the software of SolidWorks.

The qualifications of the machine are utilized for initiating the synchronous generator plan. Afterward choosing materials and determining the parameter plan. The requirements of the machine that related to the optimal factors are intially supposed before treating the circuit of electrical, the circuit of magnetic and mechanics. The current output, the cosinus phi and 
the terminal of voltage are projected can encounter the behavior of the machine. That is the final plan procedure.

The factor of optimization can be changed by reiterating the process of plan if the spesifications has not been encountered yet. The plan paper can be issued if the performance has been met the requirements. With the specific output power predetermined as a benchmark, then the calculation process can determine the appropriate air gap length in the engine planning.

The magnetic field lines passing through the air gap in the axial direction with the engine shaft serve as the basis for designing three phase axial flux machine. The stator and the rotor shaped and placed parallel to each other. The stator possessing two sides of the slot and is placed between two rotors. On the surface of stator and rotor having the slots are located the coils wire as displayed in Figure 4.

Basically, the axial flux machine is similar to the radial flux machine differs only in the cylinder-shaped rotors, so electromagnet theory is also alike. Nevertheless, for radial flux machines are more difficult than axial flux machine in the process of manufacture. The numbers assigned to the machine specification are the nominal value when the machine is fully loaded. The Output power, the terminal voltage (line to line), the frequency, the rotation of rotor, and the power factor are nominal quantities specified. In the generator shaft where a field coil is attached, it is rotated by prime mover, it is necessary to determine the input power and load torque. The steady state magnetic field in the rotor is resulted by the field current coming from the direct current source attached to it

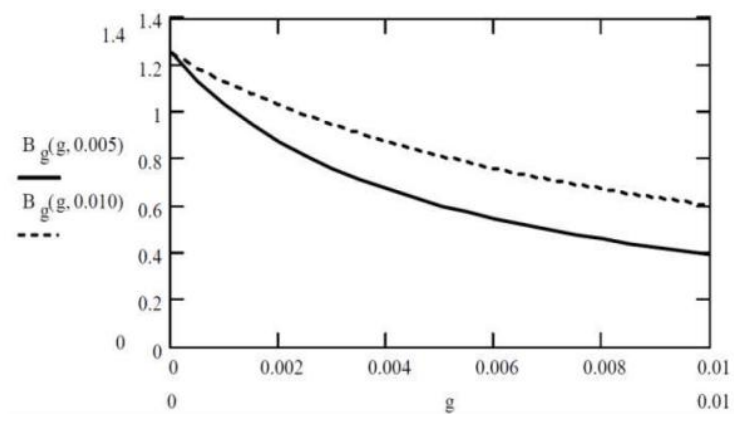

Fig. 5. Changes in air gap affecting magnetic field density.

The air gap that can be varied on the axial flux machine is one of its advantages. The unvaried permanent air gap is a disadvantage possessed by the synchronous and the induction machine of the radial flux. The field current flowing into the machine rotor coil is required larger to produce larger magnetic flux due to the larger air gap.

If the air gap gets larger then magnetic flux density will be smaller. The magnetic energy required higher when the non-magnetic air gap is getting larger. Changes in air gap affecting magnetic field densityis displayed in Figure 5.

Another advantage of axial flux machine is that its air gap can be made more than one. The testing machine here has two air gaps, one stator is located between two rotor. Equations that express the relationship between permeance, reluctance and electrical quantities on machines can be included in the design calculations. 


\subsection{The machine tests}

After the AFWR synchronous generator is assembled, the tests are done by connecting to electrical and mechanical measuring instrument at the laboratory. Initially, the test was done to inspect the construction, coils and the output of generator. The next test was done to check the rotation of generator using an inverter $2.2 \mathrm{~kW}$. Finally, the test was performed to test the full performance of AFWR generator.

To perform the tests on the generator, measuring instruments are utilized to measure the electrical and mechanical quantity. The tests performed on the AFWR generator include no load test, full load test, speed changes test, air gap changes test, short circuit test and temperature rise test. While the test performed on the AFWR motor include dc test, no load test and field current changes test.

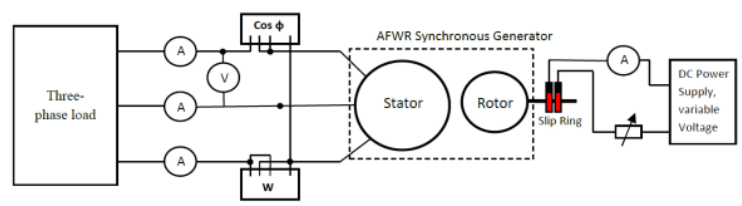

Fig. 6. The test circuit of AFWR generator

When the generator is tested, the induction motor is utilized as a prime mover to turn the shaft of the generator. The speed of the induction motor rotation is controlled by an inverter. Electrical measuring instruments consists of dc ampere meter, dc voltmeter, ac ampere meter, ac voltmeter, and clamp on tester. While the mechanical measuring instrument consists of a tachometer, calliper and filler gauge. The test circuit and equipment utilized in the tests of AFWR generator are shown in Figure 6 and 7 respectively.

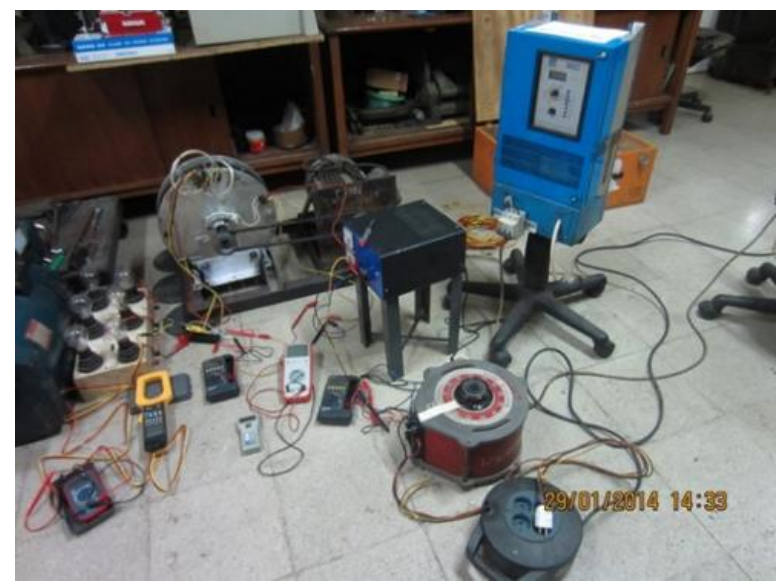

Fig. 7. The equipment utilized in the test of FWR generator.

When the generator is designed, the value of machine parameters are obtained from the calculation using MATLAB. The yield of the calculation is utilized to analyse the 
achievement of the generator which is referred to the power output. The iron losses and the mechanical (friction and windage) losses is assumed to be $5 \%$ and $1 \%$ respectively from the power output. The issue is directed at the power output and the efficiency. The power output has been assigned to a certain magnitude, while the efficiency is searched for the bigest value. By varying one of the machine parameters, then its power output and efficiency will change too.

\section{Results and Discussion}

The exact air gap length is needed to determine the optimum machine efficiency. Table 1 shows the generator working requirement needed for design. Table 2 shows the outcome of machine achievement calculations on output power of $1 \mathrm{~kW}$ and efficiency $85.30 \%$. Cosphi, stator current, line to line voltage which is another engine paremeter also changes when the air gap is changed. Examination and selection of output power and efficiency values are performed to match the rated values by spreading the length of the air gap from small to large widths.

\subsection{The machine efficiency}

The optimal efficiency is obtained from the above computation with $0.1 \mathrm{~cm}$ air gap width. The Line to line voltage at the engine terminal is $380 \mathrm{~V}$ with the air gap width of $0.1 \mathrm{~cm}$. Figure 8 shows the effect of air gap on the line to line voltage. While, figure 9 shows the relationship between the air gap changes to the efficiency.

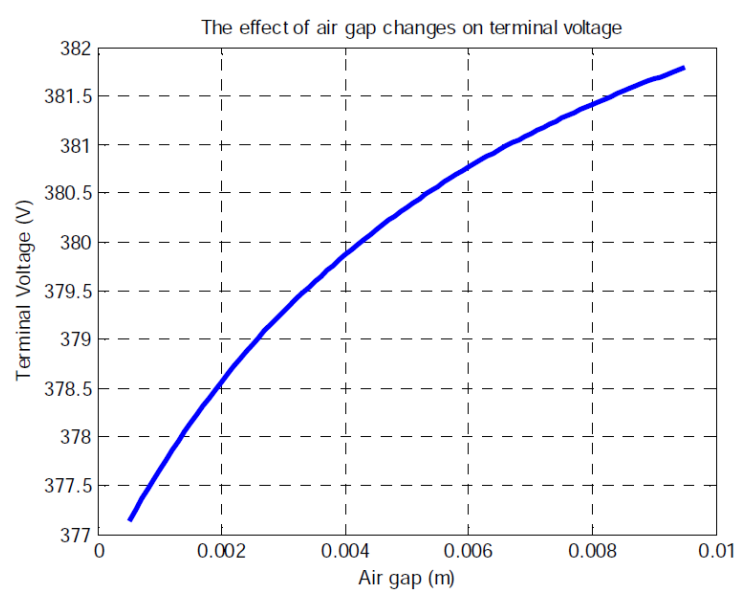

Fig. 8. The effect of air gap on the line to line voltage.

The inductive load is the dominant load connected to the generator. On this occasion also need to see how the effect on the line to line voltage on the generator.

The current, the line to line voltage, the voltage regulation and the efficiency need to be seen as a result of loading the machine with different inductive loads. Attaching Inductive load 
to the machine ranging from small to large loads with an interval of $25 \%$. The current and machine efficiency will be greater when this inductive load is higher.

But the voltage regulation is higher with decreasing line to line voltage due to the increasing inductive load. Table 2 shows the variations on current, efficiency, line to line voltage and voltage regulation due to the inductive load increase.

The result of calculation by using Matlab is obtained the efficiency of AFWR synchronous generator of $85.30 \%$. For comparison of efficiency with other types of machines that have the same output power as this generator ie. an induction motor (copper rotor) of $82.8 \%$, an asynchronous motor (single layer) of $71.5 \%$, an asynchronous motor (three-phase sinusoidal) of $76.6 \%$ and a TORUS generator of $81.18 \%$. From the above data, it is obtained that the efficiency of the four engine above lower than the efficiency of AFWR engine. The optimization parameters obtained from computing can be used for computing the above efficiency [6].

Table 2. The effect of the inductive load changes to line current, efficiency, and line to line voltage.

\begin{tabular}{|c|c|c|c|c|c|}
\hline \multicolumn{2}{|c|}{ Load } & \multirow{2}{*}{$\begin{array}{c}\text { Current } \\
(\mathrm{A})\end{array}$} & $\begin{array}{c}\text { Efficiency } \\
(\%)\end{array}$ & $\begin{array}{c}\text { Terminal } \\
\text { Voltage } \\
(\mathrm{V})\end{array}$ & $\begin{array}{c}\text { Voltage } \\
\text { Regulation } \\
(\mathrm{VR})\end{array}$ \\
\hline$(\%)$ & $(\mathrm{W})$ & & & & \\
\hline 25 & 250 & 0.447 & 58.44 & 374.76 & 1.398 \\
\hline 50 & 500 & 0.894 & 73.48 & 369.34 & 2.887 \\
\hline 75 & 750 & 1.340 & 80.37 & 363.74 & 4.472 \\
\hline 100 & 1.000 & 1.788 & 84.30 & 357.95 & 6.161 \\
\hline
\end{tabular}

In order for the winding wire to be properly located in a stator or a rotor slot, the convention is taken for the average slot fill factor on the low-voltage machine. For rectangular wires is taken for that factor of 0.6, while, for circular wires is taken 0.4. In the computation of optimization, the size of stator and rotor is fixed, as well as the size of slots.

The slot size rule plays an important role in assigning the number of coils and the size of the wire cross section. Finally, the slot fill factor determines the dimemsion of the slot. The size of the slot fill factor of 0.3629 is gained from each stator slot having 220 wires with a wire cross-section of $0.196 \mathrm{~mm}^{2}$. Picture 4 displays the stator and rotor slot filled by coils. The slot fill factor in which the slot is occupied by conductor wire according to the valid standard is 0.5 . 


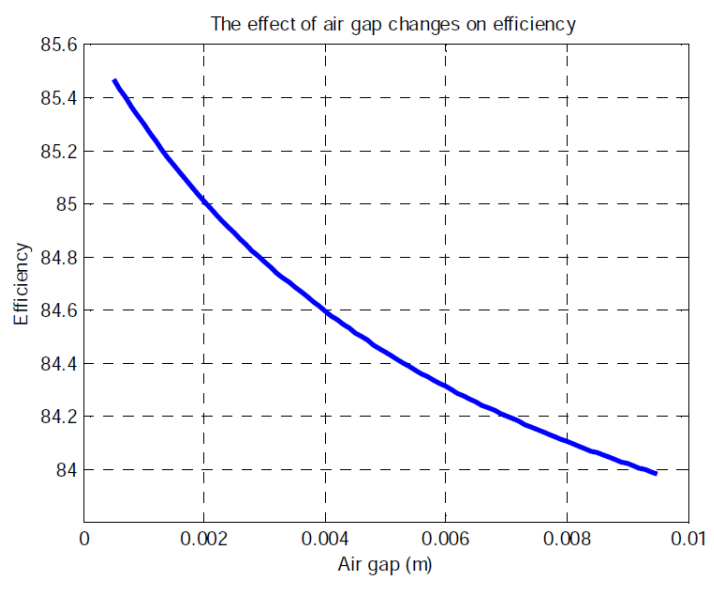

Fig. 9. Efficiency with Respect to the Air Gap.

\subsection{The relationship between losses and the efficiency}

To obtain the efficiency of AFWR motor based on the results of testing, the data required consist of power output, full-load current, copper losses, iron losses, mechanical losses, brush losses and miscellaneous losses (stray load losses). From the results of tests are obtained output power, stator current, the value of the stator resistance coil, the field winding resistance and the rotor current. The stator current and the stator resistance are needed to obtain stator copper losses and the rotor current and the rotor resistance are needed to obtain rotor copper losses and the brush losses [7].

From the above test results are achieved the three resistance on both sides of stator windings connected in parallel and the star (wye) of 13,085 $\Omega$. While the resistance on both sides of the rotor windings are connected in parallel of $0,396 \Omega$. The stator and rotor copper losses can be computed using the equations respectively:

$$
\begin{gathered}
P_{s c l}=3 I_{1}^{2} R_{1} \\
\mathrm{P}_{\mathrm{rcl}}=\mathrm{I}_{\mathrm{f}}^{2} \mathrm{R}_{\mathrm{f}}
\end{gathered}
$$

With the full load armature current of 1,60 A, the stator copper losses is $100,49 \mathrm{~W}$ and the current passing through the field winding of $20 \mathrm{~A}$, then the rotor copper losses is $158,40 \mathrm{~W}$. The core losses consists of eddy current and hysteresis losses is obtained using the equation:

$$
\mathrm{P}_{\text {core }}=0,05 P_{\text {out }}
$$

The mechanical losses consists of friction and windage losses is obtained using the equation:

$$
\mathrm{P}_{f \& W}=0,01 \mathrm{P}_{\text {out }}
$$

The electrical losses on the brush is calculated using the equation: 


$$
\mathrm{P}_{\mathrm{bcl}}=2 \Delta V_{b} I_{f}
$$

With the voltage drop on each brush $\Delta \mathrm{V}$ of $0.5 \mathrm{~V}$ (less than 1 volt), The electrical losses on the brush is $20 \mathrm{~W}$.

The miscellaneous losses (stray load losses) is calculated using the equation [8]:

$$
P_{\text {stray }}=0,2 \times P_{s c l}
$$

The stator copper losses of $100.49 \mathrm{~W}$, the stray load losses is $20.1 \mathrm{~W}$

By adding together all the losses, the total losses in the motor is 358.99 watt. Therefore the AFWR motor efficiency with the air gap of $1.5 \mathrm{~mm}$ was obtained $73.58 \%$.

In order to achieve the AFWR generator efficiency, with the same way of test and calculation on the AFWR motor, it can be seen from the following Table 3. The AFWR machine that has been made and tested has low efficiency. It is caused by the factor of electrical, magnetic and mechanical. The descriptions below explain those three factors.

The electrical factor causing the efficiency of the machine relatively low consists of electrical factor in the rotor. For the electrical factor in the rotor, that is low rotor resistance, therefore it creates high rotor current and finally an increase in copper losses. If this resistance is decreased by making the diameter of the conductor smaller, so that the copper losses will decrease.

Stator and rotor cores of AFWR machine are composed of many laminations stamped from a rolled thin steel plate. It is electrically insulated from each other in order to minimize eddy currents. When making those core, the rolled steel plates are cut or split into parts to get the lamination thickness according to the size of design calculation [9].

Table 3. The efficiency of AFWR generator and AFWR motor.

\begin{tabular}{lcc}
\hline Losses / Efficiency & AFWR Generator & $\begin{array}{c}\text { AFWR } \\
\text { Motor }\end{array}$ \\
\hline $\begin{array}{l}\text { Stator Copper } \\
\text { Losses }\end{array}$ & $100,49 \mathrm{~W}$ & $100,49 \mathrm{~W}$ \\
Rotor Copper & $181,84 \mathrm{~W}$ & $158,40 \mathrm{~W}$ \\
Losses & $50 \mathrm{~W}$ & $50 \mathrm{~W}$ \\
Core Losses & $10 \mathrm{~W}$ & $10 \mathrm{~W}$ \\
Mechanical Losses & $21,43 \mathrm{~W}$ & $20 \mathrm{~W}$ \\
Brush Losses & $20,10 \mathrm{~W}$ & $20,10 \mathrm{~W}$ \\
Stray Load Losses & $61,61 \%$ & $73,58 \%$ \\
Efficiency & & \\
\hline
\end{tabular}

A bigger eddy current and lamination short circuit called interlaminar can be appeared in the burrs of edge caused by punching and cutting. A solid core can be resulted by the burred laminations configuration caused A solid core can be appeared as result of changing the configuration from burred laminations, because core of magnetic is affecting a burr of edge. 
in the faulted area can be appeared excessive local heating cause the high eddy current of induced interlaminar [10].

The AFWR generator has two small air gaps with the size of $0.5 \mathrm{~mm}$ respectively. Setting two air gaps around the two rotor discs and one stator disc is needed with a high accurate setting, so that the same width of air gap can be obtained. Using the simple and manual tools in the setting may create unequal air gaps. Therefore, the higher excitation current due to wider air gap may appear in the field winding to meet the generator output requirement.

If the air gap is made smaller to $0.3 \mathrm{~mm}$ in order to make the excitation current smaller, so that it may create friction between rotor and stator when there is a magnetic field in the rotor. The friction appears due to inequality of air gaps or non alignment of the shaft. As a result, there is a higher mechanical losses as friction losses. Therefore, a higher input power from prime mover is needed to overcome this problem.

One of losses in the moving part of the motor is the loss of friction [11]. The friction loss is specified by the following equation:

$$
\mathrm{P}=\mathrm{k} \mathrm{C}_{\mathrm{f}} \pi \rho \omega 3 \mathrm{r} 41
$$

A surface of machine having smooth area can be revealed by coefficient of roughness Cf of 1.00. The quantities like cylinder lenght 1 , machine radius $r$, velocity of rotation $\omega$, air density $\rho$ influence the coefficient of friction $\mathrm{k}[12]$.

It is complicated to determine the moving part losses. However, it is important to determine the proper losses of the machine in order to get the accurate quantities. The friction loss can not be ignored. Therefore, the friction loss makes the efficiency of machine decrease.

\section{Conclusions}

The generator of synchronous AFWR which has been designed and tested can be operated as AFWR synchronous motor. The dominant factor causing low efficiency is the electric factor that is large field current. It creates high electrical losses in the field winding. Making the cross section of the conductor smaller, so that the current becomes smaller and the magnitude of efficiency becomes higher. This small current could significantly raise the efficiency, because the losses is directly proportional to the power of two of the current flowing in the coil. Brush voltage drop can also significantly lower power losses on machines with smaller field currents.

Acknowledgments. The authors acknowledged financial support from Directorate of Higher Education, Ministry of Education Republic of Indonesia, contract number 0263/E5/2014.

\section{References}

[1]C. Kingsley, Electric Machinery, 6e. 2003.

[2]S. J. Chapman, Electric Machinaery Fundamentals. 2003.

[3]A. Multi, "Universitas indonesia rancang bangun generator sinkron tiga fasa fluks aksial rotor belitan," 2014.

[4]J. F. Gieras, R. J. W. Kamper, and M. J., Axial Flux Permanent Magnet Brushless Machines. 2004. [5]J. F. Gieras, Advancements in Electric Machines, vol. 53, no. 9. 2013.

[6]A. Multi, I. Garniwa, and U. B. Sudibyo, "Determining the Air Gap Length of an Axial Flux Wound Rotor Synchronous Generator," vol. 17, no. 2, pp. 87-93, 2013. 
[7]W. J. W. Jiqiang, W. F. W. Fengxiang, and Y. T. Y. Tao, "Analysis of rotor losses for a high speed PM generator,” 2005 Int. Conf. Electr. Mach. Syst., vol. 2, 2005.

[8]V. K. M. Murthy, Computer-aided design of electrical machines, vol. 35, no. 4. 2008.

[9]J. Pyrhönen, T. Jokinen, and V. Hrabovcová, Design of Rotating Electrical Machines. 2008.

[10]K. Lee, J. Hong, K. Lee, S. Bin Lee, and E. J. Wiedenbrug, "A Stator Core Quality Assessment Technique for Inverter-fed Induction Machines," no. 1, pp. 1-8, 2008.

[11]H. Hamzehbahmani, P. Anderson, J. Hall, and D. Fox, "Eddy current loss estimation of edge burr-affected magnetic laminations based on equivalent electrical network - Part I: Fundamental concepts and FEM modeling,” IEEE Trans. Power Deliv., vol. 29, no. 2, pp. 642-650, 2014.

[12]D. Makuc, M. Berlec, and D. Miljavec, "Analyses and tests of interlamination short-circuits," no. 3 , pp. 115-118, 2011. 